\title{
Finite element analysis of the Circular Double Skin Tubular Concrete (DSTC) under concentric loading
}

\author{
Bambang Piscesa ${ }^{1, *}$, Mario M. Attard ${ }^{2}$, Dwi Prasetya $^{1}$, and Priyo Suprobo ${ }^{1}$ \\ ${ }^{1}$ Department of Civil Engineering, Institut Teknologi Sepuluh Nopember, Surabaya, Indonesia \\ ${ }^{2}$ School of Civil and Environmental Engineering, The University of New South Wales, Sydney NSW, \\ Australia
}

\begin{abstract}
This paper presents a numerical investigation on the behaviour of circular double-skin tubular concrete (DSTC) under concentric loading. The numerical analysis is carried out using a three-dimensional non-linear finite element package (3D-NLFEA). In DSTC specimen, the concrete is enclosed by FRP wraps at the outer tube and circular hollow steel (CHS) at the inner tube. The concrete constitutive model is based on the authors developed plasticity-fracture model which uses a non-constant plastic dilation rate for modelling concrete dilation under compression. The nonlinear buckling analysis is included in the analysis. Random material imperfection is used to induced asymmetric failure pattern. Mohr-Coulomb friction model is used to simulate the contact behaviour between concrete and CHS elements. The results from the FEA are compared with the available experimental results. From the comparison, it can be concluded that the use of the authors plasticity-fracture model is in good agreement with the test results.
\end{abstract}

\section{Introduction}

Ductility and strength enhancement of concrete under confinement has received significant attention over more than two decades. As the behavior of confined concrete under both active and passive confinement become well understood which can be reflected by looking at the number of the confinement model for concrete under compression, the research shifted to extend the optimal configuration of confining devices which combines one or two other material that provides confinement to the concrete core. These additional materials often placed outside the concrete material and it was called here as the external confining devices.

Although there were many types of combination, here the author would like to investigate the behavior of hollow concrete columns confined both at the outer and inner sides of the section. At the outer side, FRP material is used while at the inner side, the steel tube is used. The concrete material prevents outward buckling of the steel tube while FRP

\footnotetext{
* Corresponding author: piscesa@ce.its.ac.id
} 
material suppresses the concrete lateral dilations. This mechanism improves both strength and ductility of the DSTC specimen.

From the previous studies on DSTC specimens, the stiffness of the FRP jacket modulus plays the most important roles in enhancing the capacity of the DSTC. The axial stressstrain curve showed a slight softening behavior when the DSTC specimen was only lightly confined with FRP jacket $[1,2]$. However, for a medium to heavy confined DSTC specimen, the stress-strain curve shows an always hardening behavior until the failure in the FRP material. This way, the designer could design the performance of the DSTC specimen to be governed by the FRP thickness.

In building or bridge constructions, the use of DSTC specimen would reduce the concrete volume while maintaining sufficiently high inertia and stiffness. For a structure that built on a high seismic region, an always hardening behavior of DSTC columns would be very beneficial compared to a conventional RC column. DSTC specimen use lesser steel reinforcement, especially in the transverse direction. DSTC specimen does not suffer from premature cover spalling which often occurs in RC column made of high strength concrete. Moreover, the steel tube was in the inner side which would be protected against fire and corrosion. Considering the benefits mentioned above, it is important to study the behavior of DSTC specimen both under concentric and eccentric loading.

This paper presents a numerical analysis of concentrically loaded DSTC specimens using the 3D non-linear finite element analysis (3D-NLFEA) software package. The 3DNLFEA was developed by the authors [3-8]. Since the distribution of the confining pressure in concrete throughout the radius of the section was not uniform and tends to have a tensile pressure near the steel tube, the use of the plasticity-fracture model is used. Here, the authors' plasticity-fracture model [9], which is the improvement from the previous model $[10,11]$, is used as the constitutive model for concrete material. 3D-NLFEA has been used to study confinement for concrete confined with both internal and/ or external confining devices $[3,5-7]$.

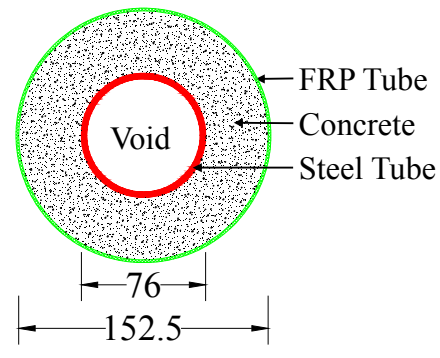

(a)

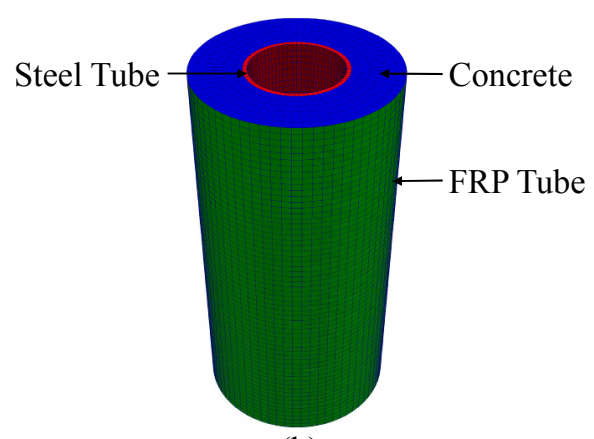

(b)

Fig. 1. (a) Cross-Sectional Dimension of D40-B1-I, II ; (b) 3D-NLFEA of D40-B1-I,II.

\section{The 3d-NLFEA Models}

In the 3D-NLFEA, all elements for concrete, FRP, and steel tube are modeled using hexahedral element. By using hexahedral elements, the stress distribution in radial direction varies. This gives more realistic stress distribution for a thick steel tube. The specimen modeled here is adapted from the available experiment tested by Teng et al. [2]. The specimens had an outer concrete diameter of $152.5 \mathrm{~mm}$ and inner concrete diameter of 76 $\mathrm{mm}$. The thickness of the steel tube is $3.3 \mathrm{~mm}$. The thickness of one ply FRP tube is 0.17 
$\mathrm{mm}$. The DSTC specimen modeled only have one ply of CFRP wraps. Fig. 1(a) shows the cross-section of the DTSC specimen modeled in this paper.

Fig. 1(b), shows the 3D model for DSTC specimen. Both ends were fixed against lateral movements, and the load is controlled using displacement at the top end of the specimen. In Fig. 1(b), the concrete element is blue colored, the steel tube element is red coloured, and the FRP element is green colored. Total 33,672 hexahedral elements are used to model the selected DSTC specimen which consists of 25,254 concrete elements, 4209 steel tube elements, and 4209 FRP elements. The stiffness of the hexahedral elements used in 3DNLFEA is integrated using selective numerical integrations. For the hydrostatic part, reduced integration is used while for the deviatoric part, and full integration is used. This kind of selective integration is also known as the BBar element technologies [12].

\section{Constitutive models of material}

\subsection{Steel tube}

The steel tube material is modeled as an isotropic material with the constitutive laws obeying the $\mathrm{J} 2$ plasticity model. A radial return mapping algorithm is employed once the trial stresses in the gauss point lie outside the failure surface. An elastic-perfectly plastic stress-strain curve is used without the steel hardening behavior. The selected DSTC specimen had a steel tube with a yield strength of $352.7 \mathrm{MPa}$ and Young's modulus of $207.3 \mathrm{GPa}$.

\subsection{Fiber Reinforced Polymer (FRP)}

The FRP material is modeled as a transversally isotropic material with an elastic behavior $[4,6,8]$. For a unidirectional fiber orientation, the stiffness in the fiber direction is much larger than the orthogonal direction. In the orthogonal direction, the stiffness of the material is set equal to the resin modulus. The CFRP consists of unidirectional carbon fiber with the ultimate tensile strength of $1825.5 \mathrm{MPa}$ and the jacket modulus of $80.1 \mathrm{GPa}$ for a single wrap. The resin modulus is set to $8.0 \mathrm{GPa}[4,8]$.

\subsection{Concrete}

The concrete material is modeled using the anisotropic material with the plasticity-fracture model as the constitutive laws. The plasticity-fracture model consists of two active failure surfaces. For concrete under compression, the failure surface uses the Menetrey and Willam [13] which was modified to include the frictional driver parameter in the formulation [10, $11,14,15]$. With the proposed frictional driver formulation, any peak and residual stresses formulations for confined concrete can be mapped into a three-dimensional failure surface. The peak stress formulation used in the model is based on the Attard and Setunge model [16] while the residual stress formulation is based on the Samani and Attard model [17].

The flow rule is non-associative. In the plastic potential function formulation, there is an additional plastic dilation rate control parameter which enables the use of non-constant plastic dilation rate formulation $[10,11]$. The plastic dilation rate formulation itself is sensitive to both the confining pressure and the lateral kinematic restraint $[4,9,11,15]$. The lateral modulus (EL) is used to evaluate the stiffness of the active lateral kinematic restraint. For concrete under tensile loading, the maximum tensile stresses were limited with the tension cut-off failure surface $[9,18]$. The tensile capacity for concrete is also affected by concrete crushing (when softens) [4, 9, 18]. For the selected DSTC specimen 
$[2,19]$, the concrete compressive strength of the specimen which was determined from uniaxial concrete cylinder test is $39.6 \mathrm{MPa}$. The concrete elastic modulus is $27,922 \mathrm{MPa}$, and the concrete uniaxial axial peak strain is 0.0028 . The Poisson's ratio of the concrete is computed using the proposed equation in [20]. The tensile concrete strength is computed based on [16].

\section{Imperfections, contact problem, and $2^{\text {nd }}$ order effects}

\subsection{Random material and geometric imperfections}

To initiate the imperfections, the authors use both random material and geometric imperfections. The use of geometric imperfection is well known [21-23]. In contrast, the use of material imperfection is rarely used. The idea to use material imperfection is to ignite a non-uniform material strength over the whole specimen as it does in reality. It will be shown later that the use of random material imperfection gives slightly distorted confining pressure contour. The random material imperfections work by generating statistically random material strength with normal distributions for each discretized element. The output of the standard deviations for concrete and steel materials are $3.16 \mathrm{MPa}$ and $14.16 \mathrm{MPa}$, respectively. The concrete and steel modulus are adjusted accordingly. For the geometric imperfection, random deformations in the lateral direction for each node in the model is initiated by invoking a random number multiplied with $0.17 \mathrm{~mm}$.

\subsection{Contact problems (steel-to-concrete and FRP-to-concrete interactions)}

The contact in DSTC specimen between concrete and steel tube is modeled using a cohesive interface element with zero thickness proposed by Goodman et al. [24]. The use of zero thickness interface element in 3D-NLFEA for a Concrete-Filled-Steel Tube has been studied by Trimarentra et al. [25]. A Mohr-Coulomb failure surface is used to define the constitutive law of the contact surface. The absolute maximum shear stress under zero normal stress is set to 2.0 MPa. Since Epoxy resin is used to attach the FRP wrap onto the outer concrete surface, a perfect bond assumption for the FRP-To-Concrete interaction is used.

\subsection{The $2^{\text {nd }}$ Order effects}

In the analysis for DSTC specimen, there are possibilities that the steel tube undergoes local buckling and sufficiently high plastic deformation (such as elephant foot), the $2^{\text {nd }}$ order effect option was enabled. In 3D-NLFEA, the $2^{\text {nd }}$ order effect is included in the analysis by always updating the nodal coordinate. A small strain assumption is used in the simulation. The recent study by the authors [3] shows that the $2^{\text {nd }}$ order effects play an important role in predicting large deformations of eccentrically loaded rectangular CFST column.

\section{Results and discussion}

\subsection{Stress-strain response}

Fig. 2 shows the axial stress in the concrete elements as a function of the axial strain of the DSTC specimen confined only with one ply of CFRP wrap [2]. In Fig. 2, the results from 
Yu et al. [1, 19] plasticity-damage model is included in the comparisons. In [1, 19], there are two types of flow rule is used. The first flow rule utilizes the equivalent FRP-confined circular section such that the whole section uses the same flow rule formulation regardless of the differences in the section shapes. The second flow rule uses the effective confining pressure and the area strain that computed from the average of the two lateral strains. From Fig. 2, it is shown that the $2^{\text {nd }}$ method provides a better prediction for the DSTC specimen. However, the $\mathrm{Yu}$ et al. [1, 19] model overestimate the axial stress prediction in the concrete.

On the other hands, the authors model predicts slightly lower axial stress distribution on the concrete material. As previously discussed, there are two models prepared to simulate the behavior of DSTC specimen. The first model is prepared only with geometric imperfection (3D-NLFEA + INT) and the second model is prepared with both the geometric and material imperfections (3D-NLFEA + INT + RND). As shown in Fig. 2, the first model shows more accurate behavior while the second model gives lower axial stress prediction after the axial strain reaches 0.008 . It is possible that after the axial strain reaches 0.008 , a major axisymmetric failure pattern occurred and led to lower residual stress in the DSTC specimen. Nevertheless, both the authors model and the Yu et al. [1, 19] model can predict the elastic stiffness and the peak stress when the axial strain is about 0.0033 .

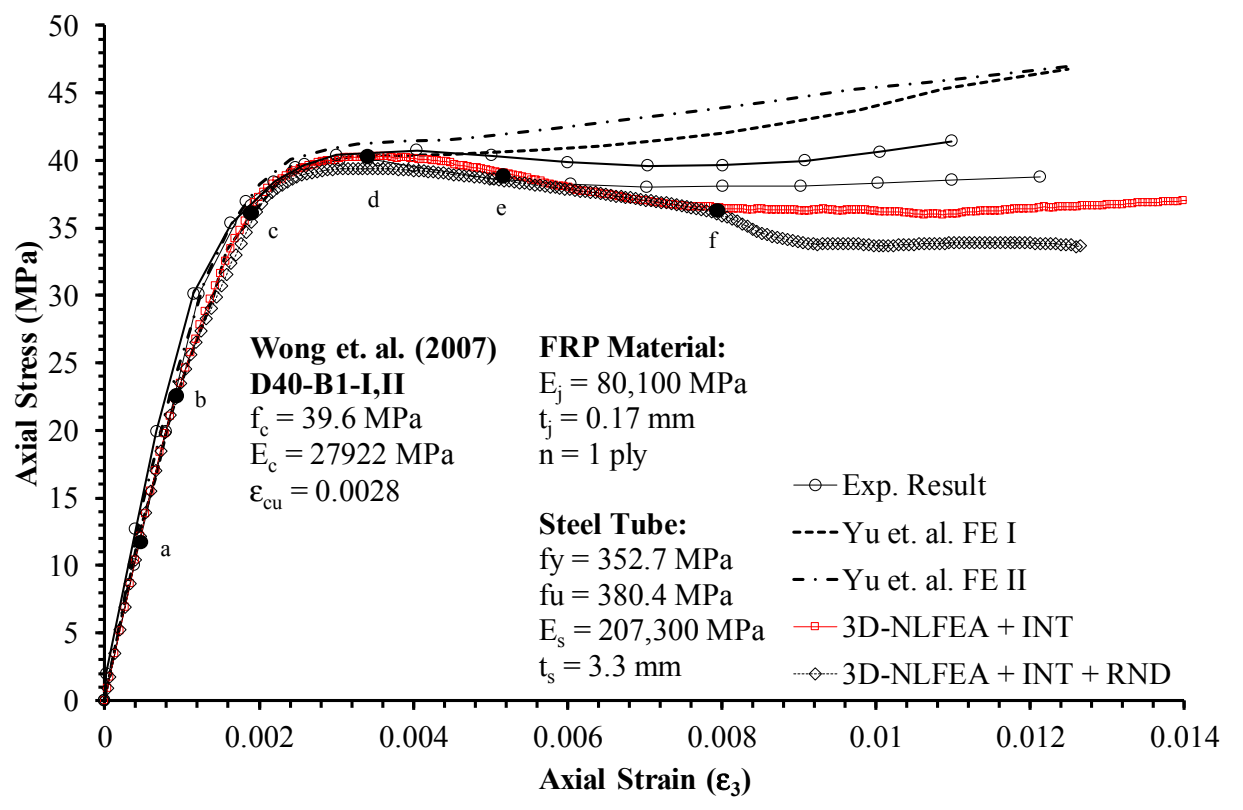

Fig. 2. Axial stress versus axial strain for specimen D40-B1-I, II.

\subsection{History and distribution of confining pressure}

Fig. 3 shows the history and distribution of confining pressure along the radial direction at the mid-height of the specimen. It should be noted that there is a slight distortion in the confining pressure contour due to the imperfections which are expected. The corresponding locations in the axial stress versus axial strain are shown in Fig. 2. Fig. 4 shows the distribution of confining pressure on the mid-height concrete thickness step by step in align with Fig. 3. In Fig. 4, it is seen clearly the evolution of the confining pressure at different steps across the thickness of the concrete element at the mid-height section. In Fig. 4, the 
thickness direction of concrete is measured from the outer concrete section (starts from 0 $\mathrm{mm}$ ) to the inner concrete near the steel tube (ends with $38.25 \mathrm{~mm}$ ).

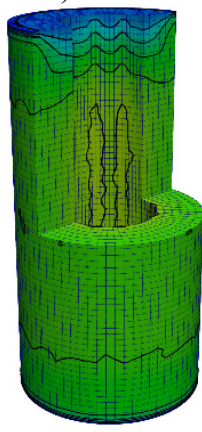

(a)

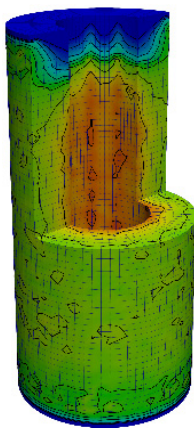

(b)

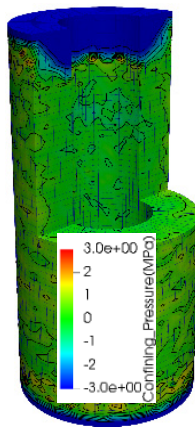

(c)

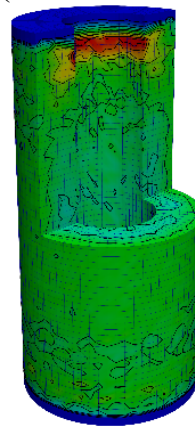

(d)

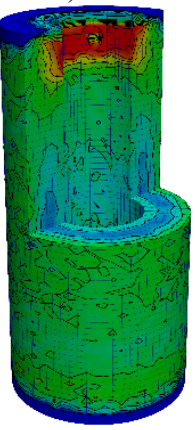

(e)

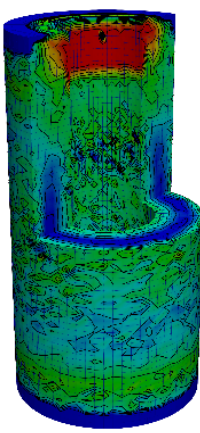

(f)

Fig. 3. Confining Pressure of Concrete in 3D-NLFEA (a) before Crack; (b) after Crack; (c) at axial strain 0.002; (d) at peak; (e) at axial strain 0.005; (f) at axial strain 0.008 .

Fig. 3(a) and Fig. 3(b) show that there is tensile stress before and after the concrete cracks (at the onset of plastic flow). Mainly due to larger Poisson's ratio of the CFRP and steel tube materials compared to the concrete material. From Fig. 4, at the onset of plastic flow, all the lateral pressure is on tension which is not beneficial but will accelerate the cracks formation in concrete. When the axial strains travel from 0.002 to 0.0033 (at peak stress), see Fig. 3(c) and Fig. 3(d), the lateral stress shifted from tension to compression. This lateral compression stress is well known as the confining pressure in which enhance the concrete strength and ductility. As the axial strain further increases, the confining pressure also increases and the largest value of confining pressure shifted from the inner concrete section to the middle concrete section as shown in Fig. 3(e) and Fig. 3(f). From point $\mathrm{f}$ in Fig. 2, it is clear that the DSTC specimen is no longer softens but continue to harden until the CFRP wrap breaks.

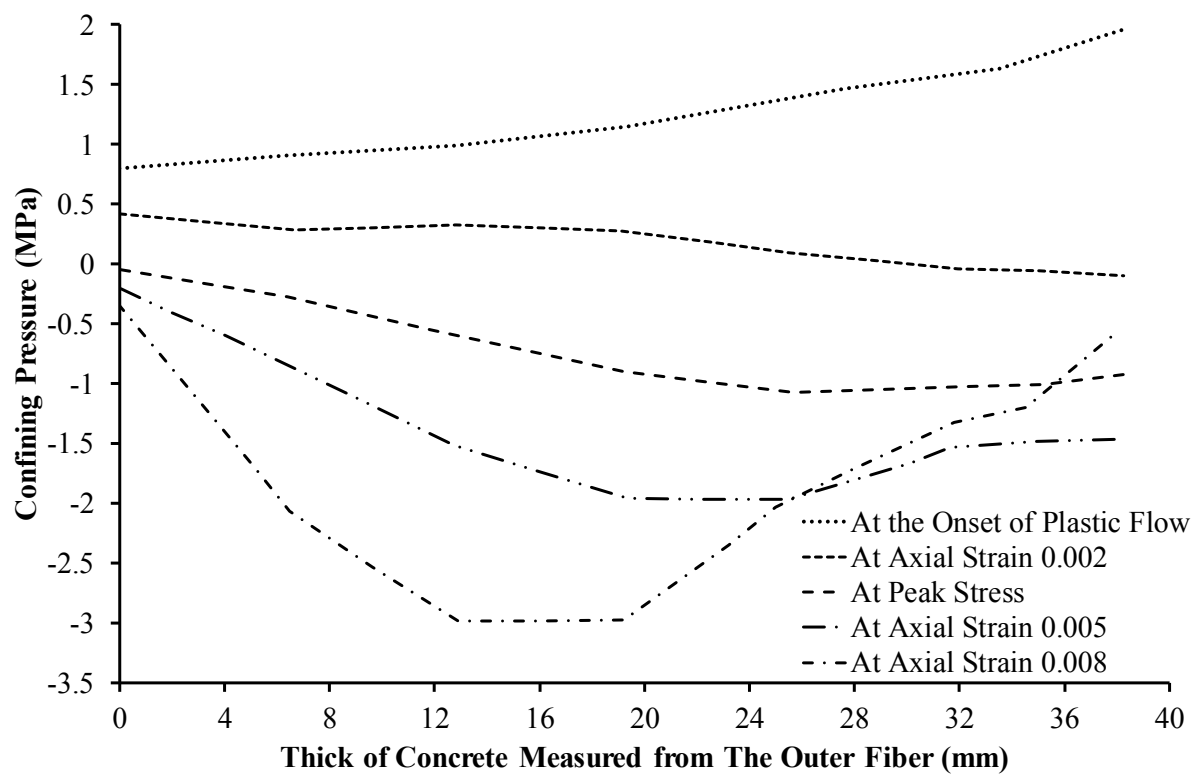

Fig. 4. The confining pressure distribution across the thickness of the concrete elements at the midheight section. 


\section{Conclusions}

This paper presents a numerical investigation on Double-Skin-Tubular-Concrete (DSTC) with a steel tube at the inner side of concrete and FRP wraps on the outer side of the concrete. The authors plasticity-fracture model was implemented inside the 3D-NLFEA software package and was used to simulate the behavior of DSTC specimen. Both material and geometric imperfections are used in the analysis. It was shown that the use of both imperfections gave slightly lower axial stress prediction and distorted the confining pressure contour. This distortion is important for further study on concrete localization and buckling of the steel tube.

This paper also presents the propagation of confining pressure across the concrete thickness for certain time steps. The purpose was to gain better insight on how the confinement works for DSTC specimen. It was found that at the onset of localized cracking, the lateral stress is tensile which would lead to accelerated cracking in concrete. However, after the concrete cracks and starts to dilate rapidly, the tensile stress shifted from tension to compression. At this stage, the concrete is under confinement. As the axial strain increases, the confining pressure also increases and starts to shift from the inner cross section into the middle cross-section. Further studies on the effect of different ply should be carried out in the future to examine whether the shifting of the confining pressure ends at the outer cross-sections.

\section{References}

1. T. Yu, J. Teng, Y. Wong, S. Dong, Eng. Struct. 32 (2010)

2. J. Teng, T. Yu, Y. Wong, S. Dong, Con. and Build. Mat. 21 (2007)

3. B. Piscesa, M.M. Attard, A.K. Samani, P. Suprobo, The Third International Conference on Civil Engineering Research (ICCER) (2017)

4. B. Piscesa, Modeling Confined Concrete Using Plasticity Formulation (Thesis, The University of New South Wales, Sydney, 2018)

5. B. Piscesa, M. Attard, P. Suprobo, A. Samani, IOP Conference Series: Materials Sci. and Eng. 267 (2017)

6. B. Piscesa, M.M. Attard, A.K. Samani, Proc. Eng. 171 (2017)

7. B. Piscesa, M.M. Attard, A.K. Samani, Proc. of the XIV International Conference on Computational Plasticity. Fundamentals and Applications (COMPLAS) (2017)

8. B. Piscesa, M.M. Attard, A.K. Samani, Comp. Struct. 194 (2018)

9. B. Piscesa, M. Attard, D. Prasetya, A.K. Samani, Modeling Cover Spalling Behavior in High Strength Reinforced Concrete Columns using A Plasticity-Fracture Model, Engineering Structures Journal, 2018 (submitted)

10. B. Piscesa, M. Attard, A. Samani, S. Tangaramvong, ACI Struct. J. 114 (2017)

11. B. Piscesa, M.M. Attard, A.K. Samani, Comp. Struct. 158 (2016)

12. T.J.R. Hughes, The finite element method: linear static and dynamic finite element analysis (Courier Corporation, New York, 2012)

13. P. Menetrey, K. Willam, ACI Struct. J. 92 (1995)

14. B. Piscesa, M.M. Attard, A.K. Samani, Proc. of the $23^{\text {rd }}$ Australasian Conference on The Mechanics of Structures and Materials (ACMSM23) (2014)

15. B. Piscesa, M.M. Attard, A.K. Samani, Proc. of the $23^{\text {rd }}$ Australasian Conference on The Mechanics of Structures and Materials (ACMSM23) (2014) 
16. M. Attard, S. Setunge, ACI Mat. J. 93 (1996)

17. A. Samani, M. Attard, Eng. Struct. 41 (2012)

18. J. Červenka, V.K. Papanikolaou, Int. J. of Plasticity, 24 (2008)

19. T. Yu, J. Teng, Y. Wong, S. Dong, Eng. Struct. 32 (2010)

20. W.P. Lokuge, J. Sanjayan, S. Setunge, J. of Mat. in Civil Eng. 17 (2005)

21. Z. Tao, Z.-B. Wang, Q. Yu, J. of Con. Steel Res. 89 (2013)

22. Y.R. Al-Ani, Thin-Walled Struct. 126 (2018)

23. H.-T. Thai, B. Uy, M. Khan, Z. Tao, F. Mashiri, J. of Con. Steel Res.102 (2014)

24. R.E. Goodman, R.L. Taylor, T.L. Brekke, J. of Soil Mech. \& Foundations Div. 94 (1968)

25. K. Trimarentra, B. Piscesa, M.M. Attard, A.K. Samani, Proc. of $13^{\text {th }}$ International Conference on Steel, Space and Composite Structures (SS18) (2018) 